\title{
Optimal tuning of PI controllers using adaptive particle swarm optimization for doubly-fed induction generator connected to the grid during a voltage dip
}

\author{
Elmostafa Chetouani, Youssef Errami, Abdellatif Obbadi, Smail Sahnoun \\ Exploitation and Processing of Renewable Energy Team, Laboratory of Electronics, Instrumentation and Energy, \\ Department of Physics, Faculty of Sciences, University Chouaib Doukkali, El Jadida, Morocco
}

\begin{tabular}{l}
\hline Article Info \\
\hline Article history: \\
Received Jan 30, 2021 \\
Revised Apr 30, 2021 \\
Accepted Jul 20, 2021 \\
\hline Keywords: \\
DFIG \\
Grid side converter \\
MPPT \\
Particle swarm optimization \\
Proportional-integral controller \\
Rotor side converter \\
Voltage dip \\
Wind energy conversion system
\end{tabular}

\begin{abstract}
This paper proposes the adaptive particle swarm optimization (APSO) technique to control the active and reactive power produced by a variable wind energy conversion system and the exchanged power between the electric grid and the system during a voltage dip (VD). Besides, to get the variable speed wind energy maximum power, a maximum power point (MPP) methodology is utilized. The system under study is a 5 MW wind turbine connected via a gearbox to a doubly-fed induction generator (DFIG). The DFIG stator is branched directly to the electrical network, while the Back-toBack converters couple the rotor to the grid. The decoupled vector control of the rotor side converter and the grid side converter is established primarily by a conventional proportional-integral (PI) and a second level by an intelligent PI whose gains are tuned using the proposed control. The performances and results obtained by APSO tuned PI controllers are analyzed and compared with those attained by classical PI controllers through the MATLAB/Simulink. The superiority of the advised technique is examined during a two-phase short-circuit fault condition and confirmed by the reduced oscillations.
\end{abstract}

This is an open access article under the CC BY-SA license.

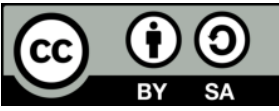

\section{Corresponding Author:}

Elmostafa Chetouani

Department of Physics, Faculty of Sciences

University Chouaib Doukkali

El Jadida, Morocco

Email: chetouani.m@ucd.ac.ma

\section{INTRODUCTION}

To have environment-friendly energy, the industry is perpetually looking for new techniques and methods whose purpose is to produce electricity from natural resources (wind, solar rays). Wind energy is generated by converting the kinetic wind energy. Recently, this energy has known great importance in the countries which invest in the sector, thanks to the immense progress made in scientific research. The most common configuration of a variable speed wind power plant (WPP) is one with a doubly-fed induction generator (DFIG), whose stator is linked directly to the grid, as indicated in [1]. However, the back-to-back converters connect the rotor to the grid, allowing for bidirectional power transfer, as seen in Figure 1. The fundamental benefit of this architecture is that the converters allow for the transmission of a percentage of the total system power, which reduces losses in power electronic components [1]. The generator control is based on the stator or rotor flux oriented (SFO or RFO) vector control approach with a conventional PI controller. Laafou, et al. [2], the rotor side converter (RSC) regulates the stator active and reactive power generated by the DFIG by controlling the rotational speed and the rotor currents using conventional PI controllers. However, the grid side converter (GSC) control maintains the DC link voltage constant. 


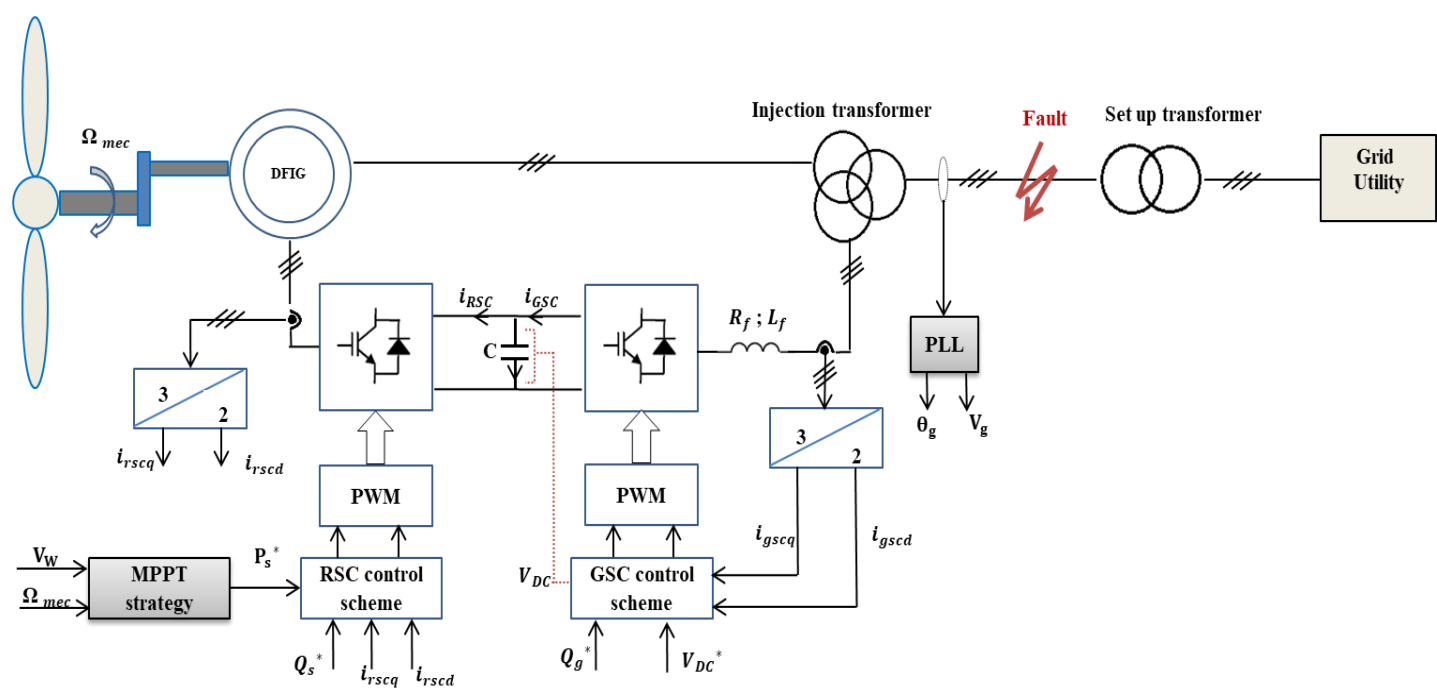

Figure 1. Synoptic scheme of the wind energy conversion system (WECS) connected to the grid

In Ahyaten and Bahaoui [3] have developed and simulated the wind power plant using a wound rotor induction generator DFIG connected via back-to-back converters GSC and RSC to the non-ideal electrical grid. Moreover, the authors carry out the control of the pitch angle. Likewise, [4] has studied different control schemes for the RSC which is utilized in the wound rotor induction generators. Examples of such control schemes are flux oriented (FOC), voltage oriented (VOC), direct torque (DTC), and direct power control (DPC). Additionally, authors in [5] have introduced the modeling of the components of DFIG based on a wind energy conversion system. The back-to-back converters and a DC link capacitor connect the rotor to the electrical network. The suggested technique is based on the feedback controller to pilot the dynamic performance of the DFIG and control the maximum produced power. Elazzaoui [6] has modeled and simulated the wind energy conversion system using a doubly-fed induction generator of $3 \mathrm{MW}$. The control scheme is based on conventional PI controllers where the gains are set by the pole compensation method. The previously mentioned articles show that the researchers did a great work modeling the wind energy conversion system and established the different control schemes, principally based on the classical PI controller. As investigated in [7], this type of control has limitations as its performances depend on calculating the conventional PI controller where the gains are constant. As well, it is still suffering from dependence on the parameters of the DFIG machine. These gains can probably change following an increase in temperature during the generator operation or when a defect occurs in the generator. The voltage dip (also denoted voltage sag) is a grid perturbation and defined as a short-duration fall in the RMS value of the voltage induced by a short circuit fault, which influences the PI controller performance [8]. Rafiee, Rafiee, and Aghamohammadi [9] has studied the effects of the voltage dip that occurred in the DFIG stator and rotor. Besides, the DFIG is extremely susceptible to grid disturbances such as voltage sag owing to short-circuit, as indicated in [10], [11]. This fault can damage the converters and provoke the wind system disconnection from the grid [12]. The authors have studied the low-voltage ride-through (LVRT) methods, which allow system protection. However, in [13], authors have proposed a comparison of the PI controller and the sliding mode technique for the grid side converter under voltage dip. To deal with the drawbacks of the traditional PI regulator, the researchers have proposed various intelligent controllers. One of the most extensively used artificial intelligence methods is particle swarm optimization (PSO). PSO is applied to get optimal gains of controllers. Taleb, Cherkaoui, and Mahfoudh [14] have applied particle swarm optimization (APSO) to enhance the performances of the PI controllers. The latter is utilized to control the rotor side converter. A comparison of the suggested controller to the conventional PI controller is established and offered. Laina et al. [15] have proposed a comparison analysis of PSO with sliding mode control (SMC). The authors compare PSO-PISMC, PSO-ISMC, and the traditional PSOSMC to show that the PSO-PISMC presents a faster transient response and a lower tracking error for a wind turbine system utilizing the DFIG. Likewise, the authors [16] have examined the overshoot anomaly of the stator and rotor currents when there is a perturbation in the grid and have proposed the PSO algorithm to tune the parameters of PI controllers for reducing the currents peak value to protect the back to back converters. In this research, we propose the APSO for tuning the gains of the PI controllers, improving the response time of the system, reducing the overshoot, and ensuring better tracking of the reference under a varying wind velocity and the grid voltage 
dip produced by a two-phase-to-ground fault. Thus, the major contributions of this article are summarized is being as:

- Modeling and simulating the proposed optimization technique for the WECS, which debiting in the grid under-voltage dip using MATLAB/Simulink.

- $\quad$ Results are compared to those found in the WECS using conventional controllers PI.

- $\quad$ The suggested method performance is analyzed in terms of the convergence of powers and the DC bus voltage.

The following is how the rest of the article is structured: The study of mathematical models of the wind power plant is covered in section 2. The study of vector control using a traditional PI for the wind chain is the focus of section 3. Section 4 highlights the APSO. Section 5 tackles the results and comparison between the two techniques.

\section{MODELING OF THE WIND ENERGY SYSTEM}

\subsection{Wind turbine modeling}

The aerodynamic power produced by the turbine is expressed as shown in (1), [17]:

$$
\mathrm{P}_{\mathrm{Tu}}=\frac{1}{2} \cdot \mathrm{Cp}(\lambda, \beta) \cdot \rho \cdot \pi \cdot \mathrm{R}^{2} \cdot \mathrm{V}_{\mathrm{w}}{ }^{3}
$$

Where $\mathrm{C}_{\mathrm{p}}$ is the turbine efficiency performance coefficient of power. This coefficient can be estimated using (2). It depends on the ratio between the linear speed of the blades and the wind speed $(\lambda)$, which is expressed as shown in (3), and the pitch angle $\beta$ [18], [19]:

$$
\begin{aligned}
& \mathrm{C}_{\mathrm{P}}(\beta, \lambda)=[0.5-0.0167 \cdot(\beta-2)] \cdot \sin \left(\frac{\pi(\lambda+0.1)}{18.5-0.3 \cdot(\beta-2)}\right)-0.00184 \cdot(\lambda-3) \cdot(\beta-2) \\
& \lambda=\frac{\text { R. } \Omega_{\mathrm{Tu}}}{\mathrm{V}}
\end{aligned}
$$

Supposing that the overall mechanical dynamics of the system are brought back to the turbine shaft, the following equations describe the model [6]:

$$
\begin{aligned}
& \mathrm{J}_{\text {tot }} \cdot \frac{\mathrm{d} \Omega_{\mathrm{mec}}}{\mathrm{dt}}+\mathrm{f} . \Omega_{\mathrm{mec}}=\mathrm{T}_{\mathrm{g}}-\mathrm{T}_{\mathrm{em}} \\
& \mathrm{T}_{\mathrm{g}}=\frac{\mathrm{T}_{\mathrm{Tu}}}{\mathrm{G}_{\mathrm{B}}} \text { and } \mathrm{G}_{\mathrm{B}}=\frac{\Omega_{\mathrm{mec}}}{\Omega_{\mathrm{Tu}}}
\end{aligned}
$$

Where $\mathrm{J}_{\text {tot }}$ is the overall inertia of WECS, $\mathrm{T}_{\mathrm{Tu}}$ is the turbine torque, $\mathrm{T}_{\mathrm{g}}$ is the gearbox torque, $\mathrm{T}_{\mathrm{em}}$ is the electromagnetic torque of the DFIG, and $\mathrm{f}$ is the overall viscosity coefficient of friction.

The MPPT algorithm is utilized to obtain the maximum power produced by the turbine. Its principle consists of controlling the electromechanical torque of the DFIG to adjust the rotation speed by maximizing the power. In this study, the MPPT with the speed regulation is selected based on a typical PI controller. The pole compensation approach is employed to determine the gains of the controller. The following are the expressions for these parameters [20]:

$$
\begin{aligned}
\mathrm{K}_{\mathrm{imppt}} & =\frac{1}{\tau \cdot \mathrm{f}} ; \text { With } \tau \text { is the system time constant } \\
\mathrm{K}_{\mathrm{pmppt}} & =\frac{-\mathrm{K}_{\mathrm{imppt}} \cdot \mathrm{J}_{\text {tot }}}{\mathrm{f}}
\end{aligned}
$$

\subsection{Modeling of the doubly-fed induction generator}

The following electrical equations can be used to define the dynamical model of the examined DFIG using the Park transformation [3], [21]:

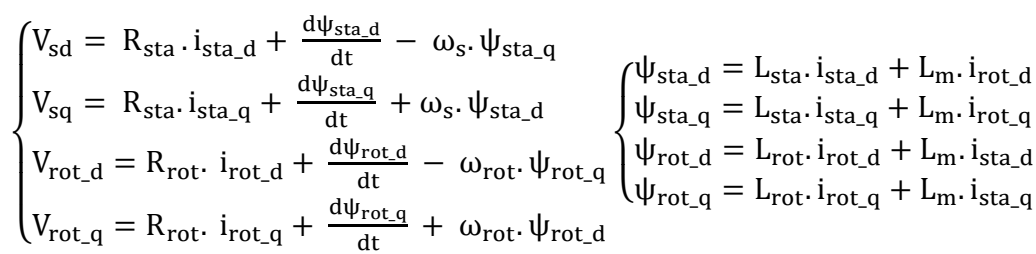


The stator and rotor voltages are $\mathrm{V}_{\mathrm{s}}$ and $\mathrm{V}_{\text {rot }}$, the stator and rotor currents are $i_{\text {sta }}$ and $i_{\text {rot }}, \psi_{\text {sta }}$ and $\psi_{\text {rot }}$ are the stator and rotor flux linkages, $R_{\text {sta }}$ and $R_{\text {rot }}$ are the stator and rotor resistances. $\omega_{\text {s }}$ and $\omega_{\text {rot }}$ are the stator and rotor angular frequencies. The stator, rotor and magnetizing inductances are $\mathrm{L}_{\mathrm{sta}}$, $\mathrm{L}_{\mathrm{rot}}$ and $\mathrm{L}_{\mathrm{m}}$, correspondingly. The electromagnetic torque can be given as [21]:

$$
\mathrm{T}_{\mathrm{em}}=-\mathrm{p} \cdot \frac{\mathrm{L}_{\mathrm{m}}}{\mathrm{L}_{\mathrm{sta}}}\left(\mathrm{i}_{\text {rot_q }} \cdot \Psi_{\text {sta_d }}-\mathrm{i}_{\text {rot_d }} \cdot \Psi_{\text {sta_q }}\right) \text {; With } \mathrm{p} \text { is the number of the DFIG pole pairs }
$$

\section{VECTOR CONTROL APPLIED TO DFIG-BASED WIND ENERGY}

\subsection{Application of the indirect vector to control the rotor converter side}

The orientation of the stator flux vector, which is oriented along the d-axis, is used to control the RSC. The phase-locked loop (PLL) strategy is employed to calculate the electrical network voltage (Vs), and the resistance of the stator windings is ignored.

$$
\begin{aligned}
& \psi_{\text {sta_d }}=\psi_{\text {sta }}, \psi_{\text {sta_q }}=0 \\
& \mathrm{~V}_{\text {sd }}=0, V_{\text {sq }}=V_{s}=\omega_{s} \cdot \psi_{\text {sta }}
\end{aligned}
$$

The rotor currents can be expressed as shown in [6], [21]:

$$
\begin{aligned}
& i_{\text {rot_d }}=\left[V_{\text {rot_d }}+\text { g. } \omega_{s}\left(L_{\text {rot }}-\frac{L_{m}{ }^{2}}{L_{s}}\right) i_{\text {rot_q }}\right] /\left[R_{\text {rot }}+\left(L_{\text {rot }}-\frac{L_{m}{ }^{2}}{L_{\text {sta }}}\right) \cdot s\right] \\
& i_{\text {rot_q }}=\left[V_{\text {rot_q }}-\text { g. } \omega_{s}\left(L_{r}-\frac{L_{m}{ }^{2}}{L_{\text {sta }}}\right) i_{\text {rot_d }}-g \cdot \frac{V_{s} \cdot L_{m}}{L_{s t a}}\right] /\left[R_{\text {rot }}+\left(L_{\text {rot }}-\frac{L_{m}{ }^{2}}{L_{s}}\right) \cdot s\right]
\end{aligned}
$$

The electromagnetic torque can be rewritten as:

$$
\mathrm{T}_{\mathrm{em}}=-\mathrm{p} \cdot \frac{\mathrm{L}_{\mathrm{m}}}{\mathrm{L}_{\mathrm{sta}}} \cdot \mathrm{i}_{\text {rot_q}} \mathrm{q} \cdot \Psi_{\text {sta }}
$$

The goal is to control the stator power independently pumped into the grid. The following equations can be used to express the stator active and reactive power [6], [21]:

$$
\begin{aligned}
& P_{s}=-V_{s q} \cdot \frac{L_{m}}{L_{\text {sta }}} i_{\text {rot_q }}=-V_{s} \cdot \frac{L_{m}}{L_{\text {sta }}} i_{\text {rot_q }}
\end{aligned}
$$

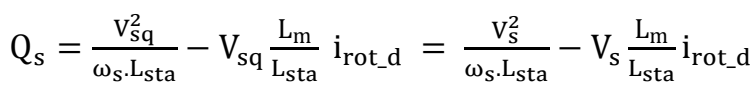

An open loop regulates the powers. The rotor currents $\left(i_{\text {rot_q }}, i_{\text {rot_d }}\right)$ are, nevertheless, controlled by a closed loop. Unlike, the current $i_{\text {rot_q }}^{*}$ is obtained from input power reference to control active power. The reactive power is controlled by regulating $i_{\text {rot_d }}^{*}$, which is computed from the $Q_{s}{ }^{*}$. These current references can be written as in [15]:

$$
\begin{aligned}
& \mathrm{i}_{\text {rot_q }}^{*}=-\frac{\mathrm{L}_{\mathrm{sta}}}{\mathrm{L}_{\mathrm{m}} \cdot \mathrm{V}_{\mathrm{s}}} \cdot \mathrm{P}_{\mathrm{s}}^{*} \\
& \mathrm{i}_{\text {rot_d }}^{*}=-\frac{\mathrm{L}_{\text {sta }}}{\mathrm{L}_{\mathrm{m}} \cdot \mathrm{V}_{\mathrm{s}}} \cdot\left(\mathrm{Q}_{\mathrm{s}}^{*}-\frac{\mathrm{V}_{\mathrm{s}}^{2}}{\omega_{\mathrm{s}} \cdot \mathrm{L}_{\mathrm{sta}}}\right)
\end{aligned}
$$

The voltage references are expressed as shown in [22]:

$$
\begin{aligned}
& \mathrm{V}_{\text {rot_q }}^{*}=\left[\mathrm{i}_{\text {rot_q }}^{*}-\mathrm{i}_{\text {rot_q }}\right] \cdot\left[\mathrm{K}_{\mathrm{p}-\mathrm{rsc} 1}+\mathrm{K}_{\mathrm{i}-\mathrm{rsc} 1} \cdot \frac{1}{\mathrm{~s}}\right]+\mathrm{e}_{\mathrm{rd}}+\mathrm{Vs}^{\prime} \\
& \mathrm{V}_{\text {rot_d }}^{*}=\left[\mathrm{i}_{\text {rot_d }}^{*}-\mathrm{i}_{\text {rot_d }}\right] \cdot\left[\mathrm{K}_{\mathrm{p}-\mathrm{rsc} 2}+\mathrm{K}_{\mathrm{i}-\mathrm{rsc} 2} \cdot \frac{1}{\mathrm{~s}}\right]+\mathrm{e}_{\mathrm{rq}}
\end{aligned}
$$

Where 


$$
e_{\text {rd }}=g \cdot \omega_{s} \cdot\left(L_{\text {rot }}-\frac{L_{m}^{2}}{L_{s t a}}\right) \cdot i_{\text {rot_d }} ; e_{\text {rq }}=g \cdot \omega_{s} \cdot\left(L_{\text {rot }}-\frac{L_{m}^{2}}{L_{s t a}}\right) \cdot i_{\text {rot_q }} ; V s^{\prime}=g \cdot \frac{V_{s} L_{m}}{L_{s t a}}
$$

Considering $\mathrm{T}_{\text {rsc }}$ the system time constant for the RSC controller, the PI gains can be determined applying the pole compensation technique as shown in:

$$
\mathrm{K}_{\mathrm{p}-\mathrm{rsc} 1,2}=\frac{1}{\mathrm{~T}_{\mathrm{rsc}}} \cdot\left(\mathrm{L}_{\mathrm{rot}}-\frac{\mathrm{L}_{\mathrm{m}}^{2}}{\mathrm{~L}_{\mathrm{sta}}}\right) \text { And } \mathrm{K}_{\mathrm{i}-\mathrm{rsc} 1,2}=\frac{\mathrm{K}_{\mathrm{prsc}} \cdot \mathrm{R}_{\mathrm{rot}}}{\left(\mathrm{L}_{\mathrm{rot}}-\frac{\mathrm{Lm}_{\mathrm{m}}^{2}}{\mathrm{~L}_{\mathrm{sta}}}\right)}
$$

\subsection{Control of the grid side converter}

The GSC is responsible for regulating DC-link voltage as well as reactive power exchanged with the grid. The grid voltage is oriented belong the q-axis and is determined by the PLL technique to elaborate the GSC control strategy. The grid voltages can be expressed as:

$$
\mathrm{V}_{\mathrm{gd}}=0 \text { And } \mathrm{V}_{\mathrm{gq}}=\mathrm{V}_{\mathrm{g}}
$$

The voltages and powers can be simplified as shown in [6], [23]:

$$
\begin{aligned}
& V_{g s c d}=-\left[R_{f}+L_{f} \cdot s\right] \cdot i_{g s c d}+\omega_{g} \cdot L_{f} \cdot i_{g s c q} \\
& V_{g s c q}=-\left[R_{f}+L_{f} \cdot s\right] \cdot i_{g s c q}-\omega_{g} \cdot L_{f} \cdot i_{g s c d}+V_{g} \\
& P_{g}=V_{g} \cdot i_{g s c q} \\
& Q_{g}=V_{g} \cdot i_{g s c d}
\end{aligned}
$$

The relation between the powers of converters can be expressed as shown in [6]:

$$
\mathrm{V}_{\mathrm{dC}} \cdot \mathrm{i}_{\mathrm{C}}=\mathrm{P}_{\mathrm{GSC}}-\mathrm{P}_{\mathrm{RSC}}
$$

The following is how the GSC power can be deducted:

$$
P_{g}=P_{G S C}=V_{d C} \cdot i_{C}+P_{R S C}
$$

Where $\mathrm{P}_{\mathrm{RSC}}$ is the rotor side converter power, which can be defined as:

$$
\mathrm{P}_{\mathrm{RSC}}=\mathrm{V}_{\mathrm{DC}} \cdot \mathrm{i}_{\mathrm{RSC}}
$$

So, the DC-link power $\left(\mathrm{P}_{\mathrm{dc}}^{*}\right)$ can be expressed as:

$$
\mathrm{P}_{\mathrm{dc}}^{*}=\mathrm{V}_{\mathrm{DC}} \cdot \mathrm{i}_{\mathrm{c}}^{*}
$$

From (26)-(29) the references of the grid currents can be derived as shown in [6]:

$$
\mathrm{i}_{\mathrm{gscq}}^{*}=\frac{1}{\mathrm{~V}_{\mathrm{g}}} \cdot\left(\mathrm{V}_{\mathrm{DC}}^{*} \cdot \mathrm{i}_{\mathrm{c}}^{*}+\mathrm{P}_{\mathrm{RSC}}\right) ; \mathrm{i}_{\mathrm{gscd}}^{*}=\frac{\mathrm{Q}_{\mathrm{g}}^{*}}{\mathrm{~V}_{\mathrm{g}}}
$$

It is assumed that the reference of reactive power is null to have a unit power factor. So, we impose a null direct current grid reference $\left(\mathrm{i}_{\text {gscd }}^{*}=0\right)$. The voltage references are expressed as shown in [23]:

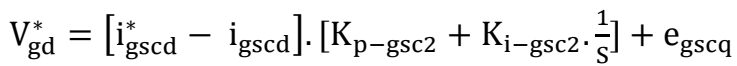

$$
\begin{aligned}
& \mathrm{V}_{\mathrm{gq}}^{*}=\left[\mathrm{i}_{\mathrm{gscq}}^{*}-\mathrm{i}_{\mathrm{gscq}}\right] \cdot\left[\mathrm{K}_{\mathrm{p}-\mathrm{gsc} 1}+\mathrm{K}_{\mathrm{i}-\mathrm{gsc1}} \cdot \frac{1}{\mathrm{~s}}\right]-\mathrm{e}_{\mathrm{gscd}}+\mathrm{V}_{\mathrm{g}}
\end{aligned}
$$

Where,

$$
\mathrm{e}_{\text {gscq }}=\omega_{\mathrm{g}} \cdot \mathrm{L}_{\mathrm{f}} \cdot \mathrm{i}_{\mathrm{gscq}} ; \mathrm{e}_{\mathrm{gscd}}=\omega_{\mathrm{g}} \cdot \mathrm{L}_{\mathrm{f}} \cdot \mathrm{i}_{\mathrm{gscd}}
$$


The expressions of the grid currents can be deduced as shown in [24]:

$$
\begin{aligned}
& i_{g s c q}=\frac{1}{\left[R_{f}+L_{f} \cdot s\right]} \cdot\left(V_{g q}^{*}-\omega_{g} \cdot L_{f} \cdot i_{g s c d}-V_{D C} \cdot S_{q}\right) \\
& i_{g s c d}=\frac{1}{\left[R_{f}+L_{f} \cdot s\right]} \cdot\left(V_{g d}^{*}+\omega_{g} \cdot L_{f} \cdot i_{g s c d q}-V_{D C} \cdot S_{d}\right)
\end{aligned}
$$

Where $S_{d}$ and $S_{q}$ are the switching states computed by Park transformation. To keep the DC-link voltage at its reference, the $\mathrm{PI}_{\mathrm{DC}}$ controller is utilized. As a result, the PI controller parameters are as shown in:

$$
K_{p-D C}=2 . \xi . \omega \cdot c \text { and } K_{i-D C}=\omega^{2} \cdot c \text {; Where } \xi \text { is the damping coefficient }
$$

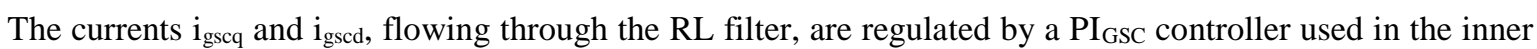
loop. Considering the time constant $\mathrm{T}_{\mathrm{gsc}}$ of the controlled system, the PI controller gains are:

$$
\mathrm{K}_{\mathrm{p}-\mathrm{gsc} 1,2}=\frac{\mathrm{L}_{\mathrm{f}}}{\mathrm{T}_{\mathrm{gsc}}} ; \mathrm{K}_{\mathrm{i}-\mathrm{gsc} 1,2}=\frac{\mathrm{R}_{\mathrm{f}}}{\mathrm{T}_{\mathrm{gsc}}}
$$

\section{ADAPTIVE PSO BASED PARAMETERS SELF-TUNING}

\subsection{Overview of PSO}

PSO is an evolutionary meta-heuristic computation methodology inspired by examining the behavior of bird flocking or fish schooling when they are hunting for food or keeping away from opponents [15], [16]. Kennedy and Eberhart devised it for the first time in 1995. The PSO is an artificial intelligence methodology based on decentralized and self-organized collective behavior. The population candidate solutions are used in the PSO methodology to find an optimal solution for a problem [18]. A fitness function determines the optimality level. The PSO method works on the notion that each particle is looking for the objective in D-dimensional space. The other particles will immediately adopt the best and ideal position that has been discovered [25].

\subsection{PSO mathematical model}

Each particle $\left(\mathrm{x}_{\mathrm{ij}}\right)$, randomly defined by initial velocity and position, tries to explore the research space through iterative test positions to achieve their objective following the expressions given by [26], [27]:

$$
\begin{aligned}
& \mathrm{V}_{\mathrm{ij}}(\mathrm{t}+1)=\mathrm{W} \cdot \mathrm{V}_{\mathrm{ij}}(\mathrm{t})+\mathrm{C}_{1} \cdot \mathrm{r}_{1} \cdot\left(\mathrm{P}_{\text {best }_{\mathrm{ij}}}-\mathrm{x}_{\mathrm{ij}}(\mathrm{t})\right)+\mathrm{C}_{2} \cdot \mathrm{r}_{2} \cdot\left(\mathrm{G}_{\text {best }_{\mathrm{j}}}-\mathrm{x}_{\mathrm{ij}}(\mathrm{t})\right) \\
& \mathrm{x}_{\mathrm{ij}}(\mathrm{t}+1)=\mathrm{V}_{\mathrm{ij}}(\mathrm{t}+1)+\mathrm{x}_{\mathrm{ij}}(\mathrm{t})
\end{aligned}
$$

Where $V_{i j}(t)$ represents the particle $i_{\text {th }}$ velocity with a j dimension at iteration $t, x_{i j}(t)$ represents the particle $i_{\text {th }}$ position with a dimension at iteration $t, P_{\text {best }}$ is the best prior position of $\mathrm{i}_{\text {th }}$ particle, $\mathrm{G}_{\text {best }}$ is the best particle among all the population, $\mathrm{W}$ is the inertia weight factor, $\left(\mathrm{C}_{1}\right.$ and $\left.\mathrm{C}_{2}\right)$ are the acceleration constants, $\left(\mathrm{r}_{1}\right.$ and $\left.\mathrm{r}_{2}\right)$ are the random integers between [0-1], and $\mathrm{n}$ is the swarm size.

\subsection{Tuning PI parameters using APSO}

The PSO algorithm calculates the optimum PI parameters [Kp, Ki]. Each particle swarm targets a minimum of the fitness function to guarantee the system stability in a closed-loop. The integral absolute error criterion (IAE) is employed as a performance index to minimize the fitness function in this research. The following expression defines the IAE [28], [29]:

$$
\mathrm{IAE}=\int_{0}^{\infty}|e(t)| \cdot d t
$$

The signal error e $(t)$ is computed by a difference between the reference input and the actual output value [27]. The weighted sum of errors, as given in (43), is determines the objective function. The target function in (44) is associated with the IAE performance criterion. By minimizing the fitness function employing the adaptive weighted PSO, the optimal parameters are obtained with fast convergence of the algorithm [28]: 


$$
\begin{aligned}
& \mathrm{F}(\mathrm{t})=\sum_{\mathrm{i}=1}^{\mathrm{d}} \mathrm{w}_{\mathrm{i}} \cdot\left|\mathrm{e}_{\mathrm{i}}(\mathrm{t})\right| \\
& \operatorname{Obj}(\mathrm{t})=\int_{0}^{\mathrm{T}} \operatorname{sim} \mathrm{F}(\mathrm{t}) \mathrm{dt}
\end{aligned}
$$

Where $\mathrm{d}$ is the dimension of the problem. The weighted factors $\left(\mathrm{w}_{\mathrm{i}}\right)$ are positive and related to the fitness function, which their sum is [29], [30]:

$$
\sum_{\mathrm{i}=1}^{\mathrm{d}} \mathrm{w}_{\mathrm{i}}=1 \text { With } \mathrm{i}=1 \ldots 5
$$

\subsection{Design of the algorithm}

The steps of the searching procedure for the PSO technique are listed as shown in [25], [27]:

- $\quad$ Step 1: Randomly generate an initial population.

- Step 2: Once a certain number of iterations have been completed, the algorithm is terminated.

- $\quad$ Step 3: Evaluate each particle's objective function and record each particle's best prior position (Pi) as well as the global best position $(\mathrm{Pg})$.

- $\quad$ Step 4: For each particle, update the improved velocity of formula (40) and the position of formula (41).

Verify the velocity constraint conditions by using the following expressions:

$$
V_{i}(t+1)=\left\{\begin{array}{c}
V_{\max } \text { if } V_{i}(t+1)>V_{\max } \\
V_{i}(t+1) \text { if } V_{\min }<V_{i}(t+1)<V_{\max } \\
V_{\min } \text { if } V_{i}(t+1)<V_{\min }
\end{array}\right.
$$

Verify the position constraint conditions of particles as shown in:

$$
x_{i}(t+1)=\left\{\begin{array}{c}
x_{\max } \text { if } x_{i}(t+1)>x_{\max } \\
x_{i}(t+1) \text { if } x_{\min }<V_{i}(t+1)<x_{\max } \\
x_{\min } \text { if } x_{i}(t+1)<x_{\min }
\end{array}\right.
$$

- $\quad$ Step 5: Go back to step 2.

\section{DISCUSSION OF SIMULATION RESULTS}

Matlab/Simulink software is employed to model, simulate, and perform the wind energy conversion system. Figure 2 presents the wind profile. The DC bus voltage reference is constant and is equal to $1200 \mathrm{~V}$ $\left(\mathrm{V}_{\mathrm{DC}}{ }^{*}=1200 \mathrm{~V}\right)$. Figure 3 shows the rated mechanical power reference, which is obtained by using the MPPT algorithm. It can be seen that when the wind profile equal to $12.5 \mathrm{~m} \mathrm{~s}^{-1}$, the rated produced power is $5 \mathrm{MW}$. The doubly-fed inductor generator is driven by the speed rotation of the multiplier output. The mechanical speed, shown in Figure 4, is obtained by the MPPT algorithm. The reactive power references $\mathrm{Q}_{\mathrm{g}}{ }^{*}$ and $\mathrm{Q}_{\mathrm{s}}{ }^{*}$ are set to 0 (VAR) to ensure a unity power factor. The pole compensation method is applied to calculate the parameters of PI controllers. These parameters, given in Table 1, are tuned by using the APSO. The configurations illustrated in Table 2 are chosen to set up the PSO program. The obtained results are compared between the conventional PI and the tuning APSO controller PI. In this paper, we analyze the active and reactive power, which are generated by the (DFIG) during the voltage dip. Figure 5 shows the grid voltage signals during a voltage dip, which occurs at 0.3 (s) and holds out 200 (ms). However, Figure 6 shows the quadrature grid current computed by the PLL. As you can see, the voltage drops by $80 \%$ due to a short circuit between two phases. Figure 7 illustrates the pattern of the reactive power during the voltage dip. The response time is ameliorated, and the ripples are significantly reduced by utilizing APSO. It can be observed by comparing the results shown in Figure 8 and Figure 9, that the active power produced by the DFIG (PsPSO) perfectly follows the reference (Ps $\left.{ }^{*}\right)$ than (Ps-PI). The response time is considerably improved to 4.3 (ms) from $10(\mathrm{~ms})$, and the static error is null in steady-state. When a grid fault happens at 0.3 (s), the PSO reduces the ripples with an ameliorated time response. The DC-link voltage computed by the traditional PI and the smart PI are shown in Figure 10. The APSO approach reduces DC link voltage overshoot to $1399 \mathrm{~V}$ from $3452 \mathrm{~V}$ and increases response time, as seen in Figure 11. The performance comparison is summarized and presented in Table 3. The comparative findings of the two proposed controls are shown in this section. Table 4 shows the characteristics of the wind power plant components used in the simulation. 


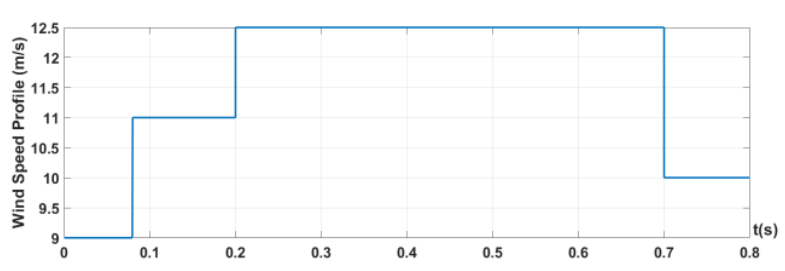

Figure 2. Wind speed profile $\left(\mathrm{m} . \mathrm{s}^{-1}\right)$

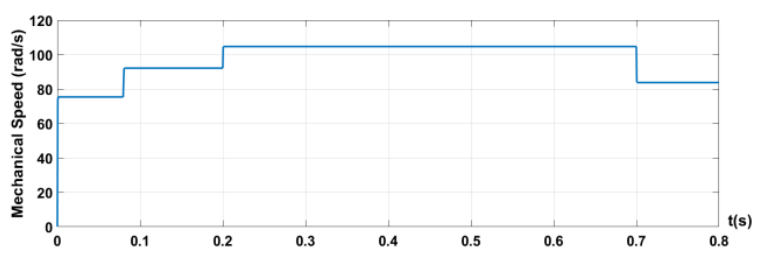

Figure 4. Mechanical speed $\left(\operatorname{rad} . \mathrm{s}^{-1}\right)$

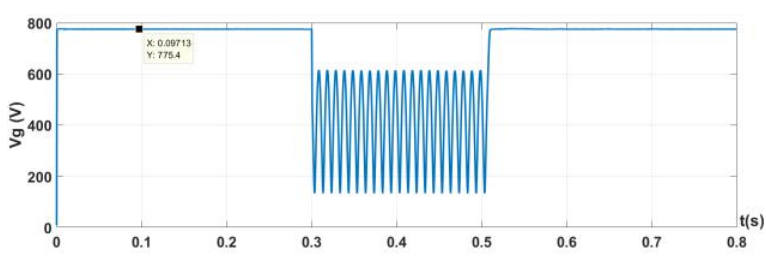

Figure 6. Quadrature grid voltage during the VD

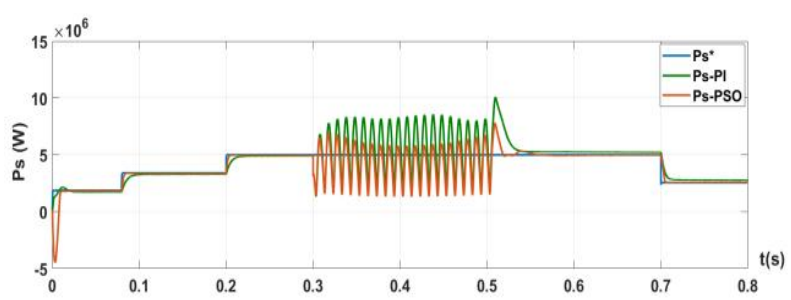

Figure 8. Active power during the VD

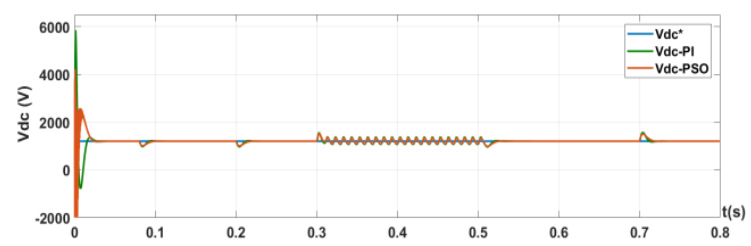

Figure 10. DC link voltage during the voltage dip

Table 1. Gains values of PI controllers

\begin{tabular}{ccc}
\hline Paramaeters & PI without APSO & PO with APSO \\
\hline Kp dc & 1,848 & 1,954 \\
Ki dc & 396 & 322,226 \\
Kp_rsc1/2 & 1,444 & $0,672 / 0,1067$ \\
Ki-rsc1/2 & 0,2369 & $0,0657 / 0,85$ \\
Kp_gsc1/2 & 200 & $176,288 / 123,929$ \\
Kigsc1/2 & $5 \mathrm{e}^{+04}$ & $4,71 \mathrm{e}+{ }^{07} / 4,1 \mathrm{e}+{ }^{07}$ \\
\hline
\end{tabular}

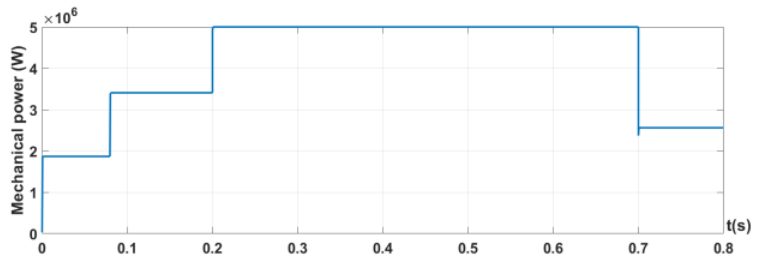

Figure 3. Mechanical power computed by the MPPT

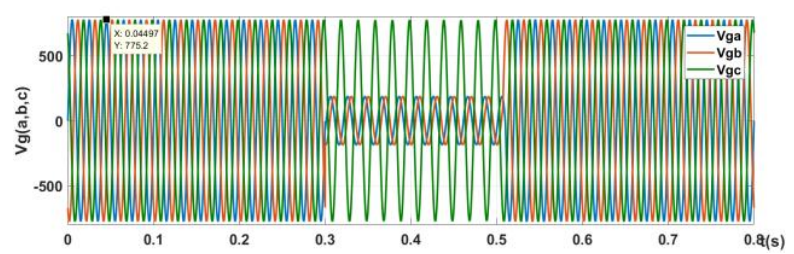

Figure 5. Grid voltage $\operatorname{Vg}(\mathrm{a}, \mathrm{b}, \mathrm{c})$ during the VD

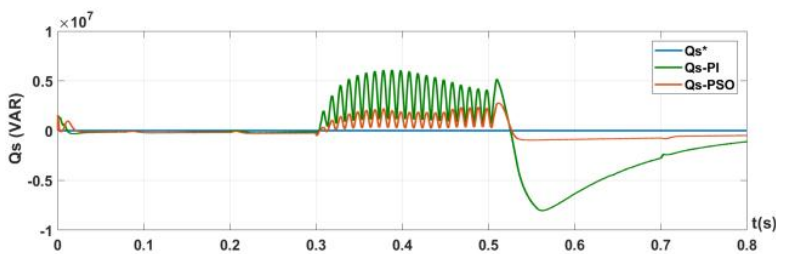

Figure 7. Reactive power during the voltage dip

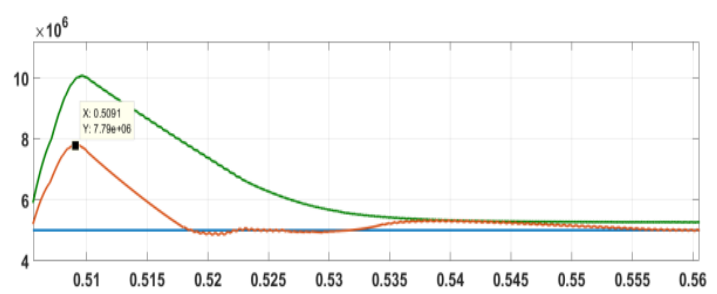

Figure 9. Active power during the VD-zoom

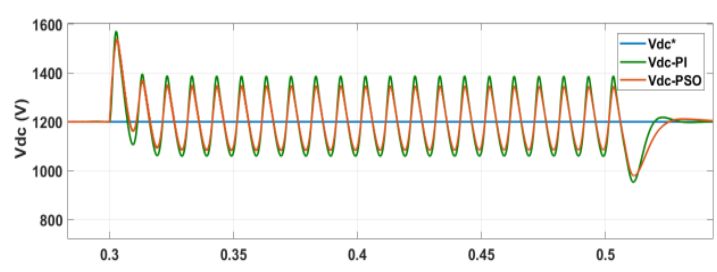

Figure 11. DC link voltage during the VD-zoom

Table 2. Parameters of PSO code

\begin{tabular}{cc}
\hline Parameters & Value \\
\hline Population size & 20 \\
Number of parameters & 10 \\
$\mathrm{~N}^{\circ}$ of iterations & 20 \\
$\mathrm{~W}$ & 0,9 \\
$\mathrm{C}_{1}=\mathrm{C}_{2}$ & 2 \\
\hline
\end{tabular}


Table 3. Performance values

\begin{tabular}{llcc}
\hline & Performance & Without APSO & With APSO \\
\hline Active Power & Response time & $10 \mathrm{~ms}$ & $4,3 \mathrm{~ms}$ \\
& Static error & $0,242.10^{6}$ & 0 \\
& Peak overshoot & $10.10^{6}$ & $7,79.10^{6}$ \\
DC link Voltage & Peak overshoot & $3452 \mathrm{~V}$ & $1399 \mathrm{~V}$ \\
\hline
\end{tabular}

Table 4. Set of parameters used in the simulation

\begin{tabular}{llcc}
\hline Components of WECS & \multicolumn{1}{c}{ Parameters } & Symbol & Value \\
\hline Turbine & Radius of blade & $\mathrm{R}$ & $51,583 \mathrm{~m}$ \\
& Coefficient of multiplier & $\mathrm{G}_{\mathrm{B}}$ & 47,23 \\
& Total moment of inertia & $\mathrm{J}_{\text {tot }}$ & $1000 \mathrm{~kg} \cdot \mathrm{m}^{2}$ \\
DFIG & DFIG rated power & $\mathrm{Ps}$ & $5 \mathrm{MW}$ \\
& Stator leakage inductance & $\mathrm{L}_{\mathrm{sta}}$ & $1,2721 \mathrm{mH}$ \\
& Rotor resistance & $\mathrm{R}_{\mathrm{rot}}$ & $1,446 \mathrm{~m} \Omega$ \\
& Rotor leakage inductance & $\mathrm{L}_{\text {rot }}$ & $1,1194 \mathrm{mH}$ \\
& Mutual inductance & $\mathrm{L}_{\mathrm{m}}$ & $0,55187 \mathrm{mH}$ \\
& Stator line to line voltage & $\mathrm{Vs}_{\mathrm{s}}$ & $950 \mathrm{~V}$ \\
Capacity & DC-link capacitance & $\mathrm{C}$ & $4400 \mu \mathrm{F}$ \\
Filter RL & Resistor of the filter & $\mathrm{R}_{\mathrm{f}}$ & $20 \Omega$ \\
& Inductance of the filter & $\mathrm{L}_{\mathrm{f}}$ & $0,08 \mathrm{H}$ \\
\hline
\end{tabular}

\section{CONCLUSION}

The WECS is modeled and simulated in this research using changing wind speed and grid voltage drop situations to verify if the recommended method is superior. The DFIG stator is directly coupled to the power system, and the rotor is connected to the grid via back-to-back converters. To modify the gains of PI controllers, intelligent PI controllers based on the APSO algorithm are created. The results of the two techniques are compared, and a $5 \mathrm{MW}$ doubly-fed induction generator is utilized to test wind chain energy. It is observed from the simulation results that the APSO tuning technique not only provides satisfactory and enthralling results but adjusts the PI controller gains to the studied system under severe conditions, notably when the wind speed changes suddenly or when the system settings change. When compared to a traditional PI controller, the APSO approach provides superior performance in terms of improved response time and lower static error. Besides, it is a good technique for tracking the wind profile variation, which is considered stochastic and variable energy. Furthermore, the APSO reduces oscillations induced by the voltage dip in RMS grid voltage substantially better than indirect vector control.

\section{REFERENCES}

[1] M. M. Alhato, S. Bouallegue, and H. Rezk, "Modeling and performance improvement of direct power control of doubly-fed induction generator based wind turbine through second-order sliding mode control approach," Mathematics, vol. 8, no. 11, pp. 1-31, 2020, doi: 10.3390/math8112012.

[2] A. J. Laafou, et al., "Dynamic Modeling and Improved Control of a Grid-Connected DFIG Used in Wind Energy Conversion Systems," Mathematical Problems in Engineering, vol. 2020, 2020, 15 pages, doi: $10.1155 / 2020 / 1651648$

[3] S. Ahyaten and J. El Bahaoui, "Modeling of Wind Turbines Based on DFIG Generator," in Multidisciplinary Digital Publishing Institute Proceedings, vol. 63, no. 1, p. 16, 2020, doi: 10.3390/proceedings2020063016.

[4] Y. K. K. Wu and W. H. H. Yang, "Different Control Strategies on the Rotor Side Converter in DFIG-based Wind Turbines," Energy Procedia, vol. 100, no. September, pp. 551-555, 2016, doi: 10.1016/j.egypro.2016.10.217.

[5] G. S. Kaloi, J. Wang, and M. H. Baloch, "Active and reactive power control of the doubly fed induction generator based on wind energy conversion system," Energy Reports, vol. 2, pp. 194-200, 2016, doi: 10.1016/j.egyr.2016.08.001.

[6] M. Elazzaoui, "Modeling and Control of a Wind System Based Doubly Fed Induction Generator: Optimization of the Power Produced, " Journal of Electrical \& Electronic Systems, vol. 4, no. 1, pp. 1-8, 2015, doi: 10.4172/23320796.1000141.

[7] R. K. Lakhe, H. Chaoui, M. Alzayed, and S. Liu, "Universal control of permanent magnet synchronous motors with uncertain dynamics," Actuators, vol. 10, no. 3, pp. 1-19, 2021, doi: 10.3390/act10030049.

[8] J. T. Jose and A. B. Chattopadhyay, "Modeling of the magnetizing phenomena of doubly fed induction generator using neuro-fuzzy algorithm considering non-linearity," International Journal of Electrical and Computer Engineering, vol. 9, no. 1, p. 23, 2019, doi: 10.11591/ijece.v9i1.pp23-33.

[9] Z. Rafiee, M. Rafiee, and M. R. Aghamohammadi, "The voltage dip and doubly fed induction generator with considering uncertainty conditions," Bulletin of Electrical Engineering and Informatics, vol. 9, no. 1, pp. 30-38, Feb 2020, doi: 10.11591/eei.v9i1.1669. 
[10] C. Chen, A. Bagheri, M. H. J. Bollen and M. Bongiorno, "The impact of voltage dips to low-voltage-ride-through capacity of doubly fed induction generator based wind turbine," 2019 IEEE Milan PowerTech, 2019, pp. 1-6, doi: 10.1109/PTC.2019.8810749.

[11] A. Loulijat, N. Ababssi, and M. Makhad, "DFIG use with combined strategy in case of failure of wind farm," International Journal of Electrical and Computer Engineering, vol. 10, no. 3, pp. 2221-2234, 2020, doi: 10.11591/ijece.v10i3.pp2221-2234.

[12] B. Qin, H. Li, X. Zhou, J. Li, and W. Liu, "Low-voltage ride-through techniques in DFIG-based wind turbines: A review," Applied Sciences, vol. 10, no. 6, 2020, doi: 10.3390/app10062154.

[13] H. Elaimani, A. Essadki, N. Elmouhi, and, R. Chakib, "Comparative Study of the Grid Side Converter's Control during a Voltage Dip," Journal of Energy, vol. 2020, pp. 1-11, 2020, doi: 10.1155/2020/7892680.

[14] M. Taleb, M. Cherkaoui, and H. Mahfoudh, "Using particle swarm optimization to enhance PI controller performances for active and reactive power control in wind energy conversion systems," IOP Conference Series Earth and Environmental Science, vol. 154, no. 1, 2018, doi: 10.1088/1755-1315/154/1/012015.

[15] R. Laina, F. E.-Z. Lamzouri, E.-M. Boufounas, A. E. Amrani, and I. Boumhidi, "Intelligent control of a DFIG wind turbine using a PSO evolutionary algorithm," Procedia Computer Science., vol. 127, pp. 471-480, 2018, doi: 10.1016/j.procs.2018.01.145.

[16] F. Wu, P. Ju and X. P. Zhang, "Parameter Tuning for Wind Turbine with Doubly Fed Induction Generator Using PSO," 2010 Asia-Pacific Power and Energy Engineering Conference, 2010, pp. 1-4, doi: 10.1109/APPEEC.2010.5449019.

[17] R. Rouabhi, "Control of the Power Generated by Variable Speed Wind," Journal of Electrical Engineering, vol.14, no. 1 , pp. 1-7, 2014

[18] Y. Bekakra and D. Ben Attous, "Optimal tuning of PI controller using PSO optimization for indirect power control for DFIG based wind turbine with MPPT," International Journal of System Assurance Engineering and Management, vol. 5, no. 3, pp. 219-229, 2014, doi: 10.1007/s13198-013-0150-0.

[19] M. Bouderbala, B. Bossoufi, A. Lagrioui, T. Mohammed, A. Hala, and Y. Ilhedrane, "Direct and indirect vector control of a doubly fed induction generator based in a wind energy conversion system," International Journal of Electrical and Computer Engineering, vol. 9, no. 3, pp. 1531-1540, 2019, doi: 10.11591/ijece.v9i3.pp1531-1540.

[20] M. Yuhendri, M. Muskhir, and T. Taali, "A novel optimum tip speed ratio control of low speed wind turbine generator based on type-2 fuzzy system," Bulletin of Electrical Engineering and Informatics, vol.8, no. 4, pp. 1189-1197, 2019, doi: 10.11591/eei.v8i4.1450.

[21] Y. Ihedrane, C. E. Bekkali, B. Bossoufi, and M. Bouderbala, "Control of power of a DFIG generator with MPPT technique for wind turbines variable speed," Green Energy and Technology, pp. 105-129, 2019, doi: 10.1007/978981-13-1945-7_5.

[22] M. A. S. Ali, K. K. Mehmood, S. Baloch, and C.H. Kim, "Modified rotor-side converter control design for improving the LVRT capability of a DFIG-based WECS," Electric Power Systems Research, vol. 186, no. April, p. 106403, 2020, doi: 10.1016/j.epsr.2020.106403.

[23] X. Zhou, Y. Zhou, Y. Ma, L. Yang, X. Yang, and B. Zhang, "DC bus voltage control of grid-side converter in permanent magnet synchronous generator based on improved second-order linear active disturbance rejection control," Energies, vol. 13, no. 18, 2020, doi: 10.3390/en13184592.

[24] P. M. Koumba, A. Cheriti, M. L. Doumbia, A. El Moubarek Bouzid and H. Chaoui, "Wind turbine control based on a permanent magnet synchronous generator connected to an Isolated electrical network," 2017 IEEE Electrical Power and Energy Conference (EPEC), 2017, pp. 1-7, doi: 10.1109/EPEC.2017.8286224.

[25] D. Wu, Q. Yang and D. Wang, "A novel PSO-PID controller application to bar rolling process," Proceedings of the 30th Chinese Control Conference, 2011, pp. 2036-2039.

[26] S. Labdai, B. Hemici, L. Nezli, N. Bounar, A. Boulkroune and L. Chrifi-Alaoui, "Control of a DFIG Based WECS with Optimized PI controllers via a duplicate PSO algorithm," 2019 International Conference on Control, Automation and Diagnosis (ICCAD), 2019, pp. 1-6, doi: 10.1109/ICCAD46983.2019.9037879.

[27] G. Shashibhushan, and S. Sonoli, "Multi-objective solution with PSO algorithm for minimization of torque ripple and speed settling time by using solar-fed 11,9 and 3-level multi-level inverter with vector control of induction motor," International Journal of Power Electronics and Drive System (IJPEDS), Vol. 11, No. 2, pp. 827-832, June 2020, doi: 10.11591/ijpeds.v11.i2.pp827-832.

[28] Z. Chen, Z. Lin, C. Yue and Y. Li, "Particle Swarm Optimized Command Filtered Backstepping Control for an Active Magnetic Bearing System*," 2018 IEEE International Conference on Information and Automation (ICIA), 2018, pp. 155-160, doi: 10.1109/ICInfA.2018.8812554.

[29] M. M. Alhato and S. Bouallègue, "Direct Power Control Optimization for Doubly Fed Induction Generator Based Wind Turbine Systems," Mathematical and Computational Applications, vol. 24, no. 3, p. 77, 2019, doi: 10.3390/mca24030077.

[30] M. Salehi Male, A. A. Majd, and R. Rasouilinezhad, "Optimal Determination of Size and Site of DGs in Mesh System Using PSO," Bulletin of Electrical Engineering and Informatics, vol. 3, no. 2, pp. 101-108, 2014, doi: 10.12928/eei.v3i2.266. 